\title{
Enrichment and characterization of a bilge microbial consortium with oil in water-emulsions breaking ability for oily wastewater treatment
}

\author{
Georgina Corti-Monzón • Melina Nisenbaum • Marcela Villegas-Plazas • \\ Howard Junca $\cdot$ Silvia Murialdo
}

Received: 22 November 2019/Accepted: 5 March 2020/Published online: 19 March 2020

(C) Springer Nature B.V. 2020

\begin{abstract}
Oily bilge wastewater is one of the main sources of hydrocarbons pollution in marine environments due to accidental or clandestine discharges. The main technical challenge for its effective treatment is the presence of stable oil-in-water $(\mathrm{O} / \mathrm{W})$ emulsions. In this work we are reporting an enriched microbial consortium from bilge wastewater with remarkable ability to demulsify oil in water emulsions. The consortium showed emulsion-breaking ratios up to $72.6 \%$ in the exponential growth phase, while the values range from 11.9 to $8.5 \%$ in stationary phase. A positive association was observed between demulsifying ability and microbial adhesion to hydrocarbons, as well as between cell concentration and demulsifying ability. Also, an interesting ability to demulsify under different temperatures, conditions of agitation, and bilge emulsions from different vessels was
\end{abstract}

Electronic supplementary material The online version of this article (https://doi.org/10.1007/s10532-020-09894-y) contains supplementary material, which is available to authorized users.

G. Corti-Monzón $(\bowtie) \cdot$ M. Nisenbaum

Instituto de Ciencia y Tecnología de Alimentos y

Ambiente, INCITAA, CONICET, Universidad Nacional

de Mar del Plata, J. B. Justo 4302, Mar del Plata 7600,

Argentina

e-mail: cortimonzon@mdp.edu.ar

G. Corti-Monzón

Facultad de Ingeniería, UNMdP, J.B. Justo 4302,

Mar del Plata 7600, Argentina observed. The Bacterial and Archaeal composition was analyzed by $16 \mathrm{~S}$ rRNA gene amplicon lllumina sequencing analyses, revealing an assemblage composed of bacterial types highly related to well characterized bacterial isolates and also to non-yet cultured bacterial types previously detected in marine and sediment samples. Hydrocarbonoclastic microbial types such as Marinobacter, Flavobacteriaceae, Alcanivorax and Gammaproteobacteria PYRIOd3 were found in high relative abundance $(27.0 \%-$ $11.1 \%$ ) and types of marine oligotrophs and surfactant degraders such as Thallasospira, Parvibaculum, Novospirillum, Shewanella algae, and Opitutae were in a group of middle predominance (1.7-3.5\%). The microbial consortium reported has promising potential for the biological demulsification of bilge wastewater and other oily wastewaters. 
Keywords Oily bilge wastewater - Microbial consortium · Biodemusification · Microbiome . Hydrocarbons

$\begin{array}{ll}\text { Abbreviations } \\ \text { HC } & \text { Hydrocarbons } \\ \text { OBW } & \text { Oily bilge wastewater } \\ \text { OWS } & \text { Oil water separators } \\ \text { TPH } & \text { Total petroleum hydrocarbon } \\ \text { MS } & \text { Marine salts } \\ \text { EBR } & \text { Emulsion breaking ratio }\end{array}$

\section{Introduction}

The hydrocarbon (HC) pollution of the oceans has a great impact in ecosystems and is a major environmental and health concern worldwide. One of the main anthropogenic inputs of $\mathrm{HC}$ in sea waters is the discharge of bilge wastewater, which is estimated to be even higher than accidental oil spills (Pavlaski et al. 2001; National Research Council (NRC) 2003; GESAMP 2007). Bilge water is the wastewater that accumulates in the bottom of the ship and it is generated from machinery leakage and wash-down of water (seawater and fresh water). It may contain fuel, hydraulic oils, lubricant oils, volatile organic compounds, metals, detergents, degreasers and other chemicals derived from activities on board (US EPA, 2008). This wastewater is a two-phase dispersive system with oil as the dispersed phase and water as the continuous phase. Dispersions of oil droplets in water are known as stable oil-in-water emulsions (Issaka 2015).

Direct discharge of untreated bilge water into the sea is prohibited by the International Maritime Organization regulation (IMO) (IMO 1988; MARPOL 1973/1978) and the total petroleum hydrocarbon (TPH) content in water that can be safely discharged into open waters should not exceed $15 \mathrm{ppm}$. Gravity Oil water separators (OWS) devices are usually employed to treat bilge wastewater employing different specific gravities of the two liquids. While gravity OWS can effectively separate discrete phases of oil and water (Koss 1996), they have low removal efficiency for separating emulsified oil droplets of less than $20 \mu \mathrm{m}$ in diameter (Woytowich et al. 1993; Caplan et al. 2000; EPA 2011), and additional polishing treatments are necessary to meet the MARPOL requirements. Typically, chemical or physical methods such as coagulation/flocculation and ultrafiltration (Peng et al. 2005), absorption and adsorption, flotation, electrochemical demulsification (EPA 2011; Rincón and La Motta 2014) are used. The requiring addition of chemical demulsifiers and cleaning or replacement of $\mathrm{HC}$ contaminated filters are some of the reasons that imply significant operational overheads (Caplan et al. 2000). The most widely employed chemical demulsifiers in the oil industry nowadays are resins of alkyl-phenol formaldehyde, copolymers of polypropylene oxide, polyethylene oxide, alkoxylated amines, alkoxylated epoxy resins types and mixtures of them (Wu et al. 2003; Xu et al. 2005; Al-sabagh et al. 2011; Adilbekova et al. 2015; Kang et al. 2018). Despite their effectiveness, these chemicals are harmful to living organisms and the extracted water must be treated before it can be released into the environment (Amirabadi et al. 2013). The increasingly stringent HC discharge requirements established by MARPOL (EPA 2011), remarks the pressing need to generate new cost-efficient, fast, non-toxic and environmentally sustainable technologies that can be applied to solve the $\mathrm{O} / \mathrm{W}$ emulsions problem. In this sense, a biological treatment is an interesting alternative.

Biodemulsifiers have attracted a great attention because of their potential applications in breaking down emulsions (Das 2001; Liu et al. 2010; Amirabadi et al. 2013; Huang et al. 2013; Zolfaghari et al. 2016). They are produced by microorganisms and compared with chemical demulsifiers, biodemulsifiers generally exhibit greater environmental compatibility, lower toxicity, higher biodegradability and better functionality under extreme conditions (Huang et al. 2012) and they can be produced from renewable and low-value substances (Liu et al. 2010). Bacterial biodemulsifiers are found either on the cell-wall (Mohebali et al. 2012) or as free extracellular components (Amirabadi et al. 2013; Hou et al. 2014). The emulsion breaking mechanisms induced by them are still under investigation.

Research on biological demulsification has primarily focused in water-in-oil emulsions (drops of water dispersed in oil), which are commonly present in oily waste sludge (Zolfaghari et al. 2016; Cai et al. 2019). However, study of the biological oil-in-water demulsification is still at a preliminary stage and few $\mathrm{O} / \mathrm{W}$ 
emulsion breaking bacteria strains (mostly of terrestrial origin) have been reported (Park et al. 2000; Das 2001; Li et al. 2012; Coutinho et al. 2013; Cai et al. 2019). Different demulsifying microorganisms have been isolated from HC contaminated sites (Das 2001; Huang et al. 2010; Mohebali et al. 2012; Salehizadeh et al. 2013) and the demulsifying capacity of a mixed bacterial culture has been characterized (Nadarajah et al. 2002). Biological studies of bilge wastewater, a residue that has high levels of emulsified $\mathrm{HC}$, have been focused on detecting HC degrading microorganisms (Nievas et al. 2006; Santisi et al. 2015) but it can also be a source of demulsifying microorganisms selected in this harsh environment, however, such biodemulsification potential has not been investigated in detail so far. The study of native microbial consortia for biological treatment of wastes may have advantages over application with non-native and pure microbes, since they are adapted to thrive in the complex toxic residue, can act synergistically and are also lowering the sterility conditions required (Gouveia et al. 2018).

The objective of this work was to enrich and detect, out of several consortia emerged from liquid bilge residues, a microbial consortium with remarkable demulsifying ability. We tested and characterized its demulsifying ability, defined the nature of its microbial composition and assessed its potential practical use in the treatment of bilge wastewater emulsions.

\section{Materials and methods}

\section{Culture enrichment}

In order to find a consortium of autochthonous microorganisms with demulsifying ability, several microbial consortia were isolated and maintained as mixed complex cultures arising from oily bilge wastewater of different ships of the port of Mar del Plata, Buenos Aires, Argentina (Latitude $38^{\circ} 00^{\prime} \mathrm{S}$; Longitude $57^{\circ} 33^{\prime} \mathrm{W}$ ). Flasks of $500 \mathrm{~mL}$ with $300 \mathrm{~mL}$ of sterile marine salts [MS: $\mathrm{NaNO}_{3} 2 \mathrm{~g} / \mathrm{L}$ and phosphate solution $4 \mathrm{~mL} / \mathrm{L}\left(\mathrm{Na}_{2} \mathrm{HPO}_{4} \cdot 12 \mathrm{H}_{2} \mathrm{O} 20 \mathrm{~g} / \mathrm{L}\right.$ and $\mathrm{NaH}_{2} \mathrm{PO}_{4} \cdot \mathrm{H}_{2} \mathrm{O} 4 \mathrm{~g} / \mathrm{L}$ in seawater, $\mathrm{pH}$ 8] (Nievas et al. 2006) with $0.5 \%$ (v/v) of different non- sterile oily bilge waste were kept in an orbital shaker (Shaker Pro, Vicking SRL) at $150 \mathrm{rpm}$ and $25 \pm 2{ }^{\circ} \mathrm{C}$. Every fifteen days, $50 \%$ of the culture volume was depleted and then replenished to the same volume of MS combined with oily bilge wastewater (OBW) $(0.5 \%$, $\mathrm{v} / \mathrm{v})$. The process of culture media replenishment was continuously repeated over the span of two years. Microbial growth was analyzed by optical density $\left(\mathrm{OD}_{600} \mathrm{~nm}\right)$ measurements through time. Culture stability was tracked down following growth curves. The demulsifying ability of the consortia was analyzed as described below for the eight microbial consortia isolated. The consortium that showed remarkable and consistent demulsifying ability retained over several rounds of culturing was finally selected for its further characterization. This flask served as a mother culture for all microbial growth curves performed in this study.

Preparation of the emulsions

Bilge water model emulsion (IMO emulsion) was prepared according to International Maritime Organization, Marine Environmental Protection Committee resolution MEPC107 (49) (adopted on 18th July 2003, Revised Guidelines and Specifications for Pollution Prevention Equipment for Machinery Space Bilges of Ships). This resolution has the specifications related to the test for the approval of OWS. The bilge water model emulsion described in this resolution (Test fluid "C") was used in this work at a laboratory scale. Briefly, $1 \mathrm{~L}$ of IMO emulsion was prepared (with a digital mechanical mixer at $13,000 \mathrm{rpm}$ for $5 \mathrm{~min}$ ) mixing fresh water with $1.53 \mathrm{~mL}$ of marine residual fuel oil in accordance with ISO 8217, type RMG 35 (density at $15{ }^{\circ} \mathrm{C}$ not less than $980 \mathrm{~kg} / \mathrm{m}^{3}$ ); $1.83 \mathrm{~mL}$ of marine distillate fuel oil in accordance with ISO 8217 , type DMA (density at $15^{\circ} \mathrm{C}$ not less than $830 \mathrm{~kg} / \mathrm{m}^{3}$ ); $0.03 \mathrm{~g}$ of sodium salt of dodecylbenzene sulfonic acid and $0.1 \mathrm{~g}$ of ferrous ferric oxide $\left(\mathrm{Fe}_{3} \mathrm{O}_{4}\right)$. The emulsion was stable over time and was stored at $4{ }^{\circ} \mathrm{C}$ for a maximum of 6 days. The emulsion was stirred for $5 \mathrm{~min}$ before taking samples for the assays. The model emulsion type was confirmed by Oil Red O test as described elsewhere (Lee and Lee 2000) using the hydrophobic Sudan Red III dye. A drop of concentrated dye was added to $1 \mathrm{~mL}$ of the emulsion and the mixture was vortexed and then studied by wet mount optic microscopy $(900 \times$ magnifications, Nikon Eclipse E-200). The observation of red oil drops on a light background confirmed the $\mathrm{O} / \mathrm{W}$ emulsion.

For the real bilge water emulsions, an aliquot of the oil and water phases of bilge wastes (from different 
ships of Mar del Plata-port: deep sea fishing ship; dredge ship; oceanographic ship and coastal fishing boats) were placed in tubes and shaken for $1 \mathrm{~min}$ at the maximum speed.

\section{Demulsification test}

The demulsification test (bottle test) was conducted as Cai et al. (2019) reported, but with some modifications. Two $\mathrm{mL}$ of cell culture was added to a test tube containing $15 \mathrm{~mL}$ of the IMO emulsion. The test tubes were vortexed $30 \mathrm{~s}$ to achieve complete mixing and then left undisturbed in an upright position at $25 \pm 2$ ${ }^{\circ} \mathrm{C}$ from 24 to $48 \mathrm{~h}$. Controls consisting of $2 \mathrm{~mL}$ of MS $(\mathrm{pH} 8)$ and $15 \mathrm{~mL}$ of emulsion were run in parallel in each experiment. Isolation of the demulsifying mother culture as well as the subsequent microbial growth assays prepared from said culture were done with mineral salts buffer at $\mathrm{pH} 8$ (Nievas et al. 2006), which allowed the correct development and enrichment of the microbial consortium and the maintenance of demulsifying ability. This $\mathrm{pH}$ remained constant throughout the microbial growth curves. Therefore, in all the experiments, the $\mathrm{pH}$ of the control sample or consortium sample was 8. All experiments were carried out in triplicates and three independent experiments were done for each condition assayed.

Due to the fact that the IMO emulsion had an intrinsic brown color, the demulsification was considered positive when a clarification of the emulsion and the appearance of a small layer of $\mathrm{HC}$ on the surface of the emulsion was visible to the naked eye. This demulsification was confirmed by optic microscopic observation (Nikon Eclipse E-200) of the water phase of the test tubes, the measurements of TPH and the transmittance values of the water phase (see later sections).

In the in movement demulsification test, the tube tests were placed in an upright position on shakers with orbital shaking $(150 \mathrm{rpm})$ or reciprocal shaking (65 rpm).

To analyze the effect of incubation temperature on the demulsification process, the test tubes were left undisturbed in an upright position at 4,12 or $25 \pm 2$ ${ }^{\circ} \mathrm{C}$ for $48 \mathrm{~h}$.

The demulsification performance was evaluated by the emulsion breaking ratio calculated according to the transmittance values of the aqueous phase, as described below.
Transmittance spectrum

The transmittance spectrum of the emulsions after $48 \mathrm{~h}$ of starting the bottle test was analyzed. For this purpose, $100 \mu \mathrm{L}$ of the emulsion to be analyzed was taken and placed in $900 \mu \mathrm{L}$ of distilled water. The transmittance spectrum was analyzed between wavelengths from 200 to $600 \mathrm{~nm}$ at one-second intervals. The transmittance of distilled water was considered as $100 \%$ in the whole spectrum and was used as baseline in all spectra scanning. At small dispersed phase concentrations light transmittance is a sensitive function of concentration, so light transmittance of emulsions decreases with the increase of the dispersed phase concentration (Cengel et al. 1961).

The demulsification performance was evaluated by the emulsion breaking ratio calculated according to the transmittance values of the aqueous phase. The area under curve (AUC) was calculated from transmittance (\%) vs. wavelength (200 to $600 \mathrm{~nm}$ ) graphs employing GraphPhad prims-5 tools. An area under the curve of 40,000 arbitrary units was considered as $100 \%$ of demulsification. This area corresponds to the transmittance of distilled water, which was set as $100 \%$ in the whole spectrum.

Emulsion breaking ratio (EBR)

$$
=\left(1-\frac{40,000-A U C}{40,000}\right) \times 100 \%
$$

Each EBR was normalized as EBRn using the following equation:

$$
\text { EBRn }=\frac{(\text { EBRsample }- \text { EBRcontrol })}{1-\text { EBRcontrol }} \times 100 \%
$$

\section{Quantitative analysis of TPH}

The TPH determination was carried out in an IR Oil Content Analyzer (HC-404 Buck Total Petroleum Hydrocarbon Analyzer), which has a fixed wavelength $2930 \mathrm{~cm}^{-1}(3.42 \mu)$. The HC extraction was done following the 418.1 EPA method, with perchlorethylene (Biopak) as extracting solvent.

Microscopic observation of the emulsion

Microscopic observations were done as Wen et al. (2010). Briefly, $15 \mu \mathrm{L}$ of the emulsion to be tested was carefully taken from the tube test, with a Pasteur 
pipette, placed on a slide and covered with a $24 \times 24 \mathrm{~nm}$ cover glass. The preparation was left to rest for $2 \mathrm{~min}$ and then was observed under an optic microscope with a $900 \times$ magnification (Nikon Eclipse E-200). Photographs were taken using a camera adapted to the ocular. Three independent replicates of each trial were made and at least five drops of each sample were analyzed. Average oil drops size was determined using ImageJ 1.52 software.

\section{Oil spreading assay}

Two hundred $\mu \mathrm{L}$ of crude oil were placed on the surface of $20 \mathrm{~mL}$ of distilled water and allowed to disperse for a few minutes to form a dark HC layer over the water. Then, $50 \mu \mathrm{L}$ of bacterial suspension or MS (control) were added on the oil surface. In presence of a biodemulsifier (which alter the contact angle at the oil-water interface), the oil will be displaced with an oil free clearing (Sabati and Motamedi 2018).

\section{Cell surface hydrophobicity}

Cell surface hydrophobicity was evaluated by microbial adherence to HC (MATH), as described in Rocha e Silva et al. (2017). The consortium was grown in $300 \mathrm{~mL}$ of MS containing OBW $(0.25 \%, \mathrm{v} / \mathrm{v})$ as the sole carbon source, at $25 \pm 2{ }^{\circ} \mathrm{C}$ with orbital agitation $(150 \mathrm{rpm})$. Culture samples were taken at different time of the growth curve. The cells were pelleted by centrifugation $(9.000 \mathrm{~g}, 10 \mathrm{~min})$, washed and resuspended in PUM buffer, pH $7\left(22.2 \mathrm{~g} \mathrm{~K}_{2} \mathrm{HPO}_{4} .3 \mathrm{H}_{2} \mathrm{O}\right.$, $7.26 \mathrm{~g} \mathrm{KH}_{2} \mathrm{PO}_{4}, 1.8 \mathrm{~g}$ urea, $0.2 \mathrm{~g} \mathrm{MgSO}_{4} .7 \mathrm{H} 2 \mathrm{O}$ and 1 $\mathrm{L}$ of distilled water) to an initial $\mathrm{OD}_{600 \mathrm{~nm}}$ of 0.4-0.6. Subsequently, $300 \mu \mathrm{L}$ of $\mathrm{n}$-hexadecane was added to $1.5 \mathrm{~mL}$ of the cell suspension. The mixture was vortexed at high speed for $1 \mathrm{~min}$ and left undisturbed for $30 \mathrm{~min}$. Then, the final $\mathrm{OD}_{600 \mathrm{~nm}}$ of the aqueous phase was measured again. Hydrophobicity was expressed as the percentage of cell adherence to nhexadecane calculated as follows:

MATH $\%:=1-\left(\frac{\text { OD600 } \mathrm{nm} \text { final }}{\text { OD600 } \mathrm{nm} \text { inicial }}\right) \times 100 \%$
High MATH values indicate high affinity of the cells for HC. For a given sample, three independent determinations were carried out.

Effect of culture age and localization of the demulsifying activity

The consortium (initial $\mathrm{OD}_{600 \mathrm{~nm}}$ of 0.1 ) was grown in flask of $500 \mathrm{~mL}$ with $300 \mathrm{~mL}$ of sterile MS containing OBW $(0.25 \%, \mathrm{v} / \mathrm{v})$ as the sole carbon source with orbital agitation $(150 \mathrm{rpm})$ at $25 \pm 2{ }^{\circ} \mathrm{C}$. An aliquot of stock culture in exponential growth phase was taken to obtain the inoculums. The microbial growth was followed by $\mathrm{OD}_{600 \mathrm{~nm}}$ changes over time. Culture samples were taken at different times during microbial growth, and the demulsifying activity of the culture was followed as previously described. To determine if the demulsifier is cell wall associated or free extracellular, the same samples were centrifuged $(9000 \mathrm{~g}$ for $10 \mathrm{~min}$ ) and the demulsifying activity of the pelleted cells re-suspended in MS or from the supernatant was evaluated.

\section{Effect of physical treatments}

Seventy hours old culture samples were submitted to moist heat under pressure (autoclaved $121^{\circ} \mathrm{C}, 20 \mathrm{~min}$ ) or ultrasound (sonicated at $4{ }^{\circ} \mathrm{C}, 30 \mathrm{~s}$ pulses at an amplitude output of 40, separated by 1 min intervals and repeated 8 times, Sharp Silent Sonic Model UT204). After these treatments, the demulsifying ability was analyzed.

\section{Effect of culture concentration}

A correlation between $\mathrm{OD}_{600 \mathrm{~nm}}$ and number of cells per milliliter was done, using a Neubauer Improved Chamber (Reichert, Bright-Line) observed under a Nikon E200 optic microscope with phase contrast, and $100 \times / 1.25$ NA objectives. A regression line with the following form was obtained: $y=7 \times 10^{8} x$ $\left(\mathrm{R}^{2}=0.844\right)$; where $y=$ number of cells $/ \mathrm{mL}$ and $x=$ $\mathrm{OD}_{600 \mathrm{~nm}}$.

Seventy hours-old culture samples $(0.2 \mathrm{~mL}$, $0.5 \mathrm{~mL}, 1 \mathrm{~mL}$ and $2 \mathrm{~mL}$ ) were taken and placed in 
tube tests containing $15 \mathrm{~mL}$ of IMO emulsion. The total volume was brought to $15 \mathrm{~mL}$ with $\mathrm{MS}$ and the demulsification activity was evaluated as previously described. The efficiency was defined as the relation between observed and maximal EBR obtained (Eff. = EBR obs./EBR. max.) after $48 \mathrm{~h}$ of starting the assay.

DNA extraction, amplification and analysis of the 16S rRNA gene amplicons

A sample of bacterial cells in exponential growth phase was collected from the mother culture of the consortium exhibiting higher and consistent demulsifying ability used in all the short term experiments reported in this study. As described above, this consortium resulted from the parallel screening for remarkable demulsification of several consortia that were maintained for two years, being subcultured each 2 weeks to $50 \%$ volume replenishment of MS combined with oily bilge wastewater (OBW) $(0.5 \%, \mathrm{v} / \mathrm{v})$ (see culture enrichment section of Materials and Methods). Cells were harvested by centrifugation at $10,000 \mathrm{~g}$ for $10 \mathrm{~min}$ and the cell pellet was resuspended in $70 \%(\mathrm{v} / \mathrm{v})$ ethanol and stored at $4{ }^{\circ} \mathrm{C}$ for DNA extraction using the protocol recently reported (García-Bonilla et al. 2019). The primers used were 15F (Parada)-806R (Apprill), forward-barcoded: FWD:GTGYCAGCMGCCGCGGTAA; REV:GGAC TACNVGGGTWTCTAAT targeting highly conserved regions in Archaea and Bacteria and targeting the amplification of hypervariable region $\mathrm{V} 4$ of the $16 \mathrm{~S}$ rRNA gene. The analysis was performed according to the workflow proposed in the Qiime package version 1.9.1 (Caporaso et al. 2010). Sequences with more than $97 \%$ similarity were grouped into operational taxonomic units (OTUs). The centroid sequences representative of each OTU were analyzed against the SILVA 132 database (version 132, released April, 2018) using the Naïve Bayesian Classifier (Wang et al. 2007). Complete description of the amplicon sequencing protocol and the bioinformatics pipeline is available in the Online Resource 1. The raw sequences produced and analyzed in this manuscript had been deposited in ENA (European Nucleotide Archive) https://www.ebi.ac.uk/ena and can be found under the Accession Number: PRJEB36636.

\section{Results and discussion}

Enrichment of the consortium and demulsifying activity

In order to find a consortium of autochthonous microorganisms of bilge wastewater with demulsifying ability, several consortia were isolated from the enrichment of microorganisms present in different bilge wastewater samples (from different ships), employing oily bilge phases as the only carbon source. The demulsifying ability of the consortia was analyzed with the bottle test using a model bilge emulsion (IMO emulsion) and visual inspection of readily distinct qualitative differences to the naked eye, specifically clarification of the emulsion and appearance of a small layer of $\mathrm{HC}$ on the emulsion surface. Of eight screened microbial consortia along the two years of parallel enrichments and fresh subculturing, only one showed a remarkable and consistent ability to demulsify the synthetic bilge emulsion (Fig. 1), therefore this consortium was further maintained and selected for the additional tests and characterizations reported below. Between 24 and $48 \mathrm{~h}$ of demulsification, a clarification of the emulsion and the appearance of a layer of $\mathrm{HC}$ on the surface were observed in the tube treated with the selected microbial consortium (Fig. 1a). After $24 \mathrm{~h}$ (Fig. 1a) a discoloration gradient of the emulsion was observed from the lower zone of the tube to the upper zone. At $48 \mathrm{~h}$ of rest, a uniform clarification of the treated emulsion was observed, accompanied by a large decrease in the number of drops of the aqueous phase, as well as a large increase in transmittance (Fig. 1b) and a statistically significant decrease of $76.6 \%$ in TPH levels (Fig. 1b). The increase in the transmittance of the light after the treatment should be due to the decrease in the coloration of the emulsion, caused by the demulsification of the HC (Cengel et al. 1961).

Demulsification consists of two-step process. Flocculation is the first step, in which droplets aggregate and even touch each other at certain points, forming flocs. Next, coalescence occurs, in which water droplets coalesce to form larger droplets which favor the phase separation (Kokal 2005). Microscopic observations of samples, taken four hours after the beginning of the demulsification, showed the presence of HC droplets flocs in the microbial consortium-treated emulsion 


\section{a}

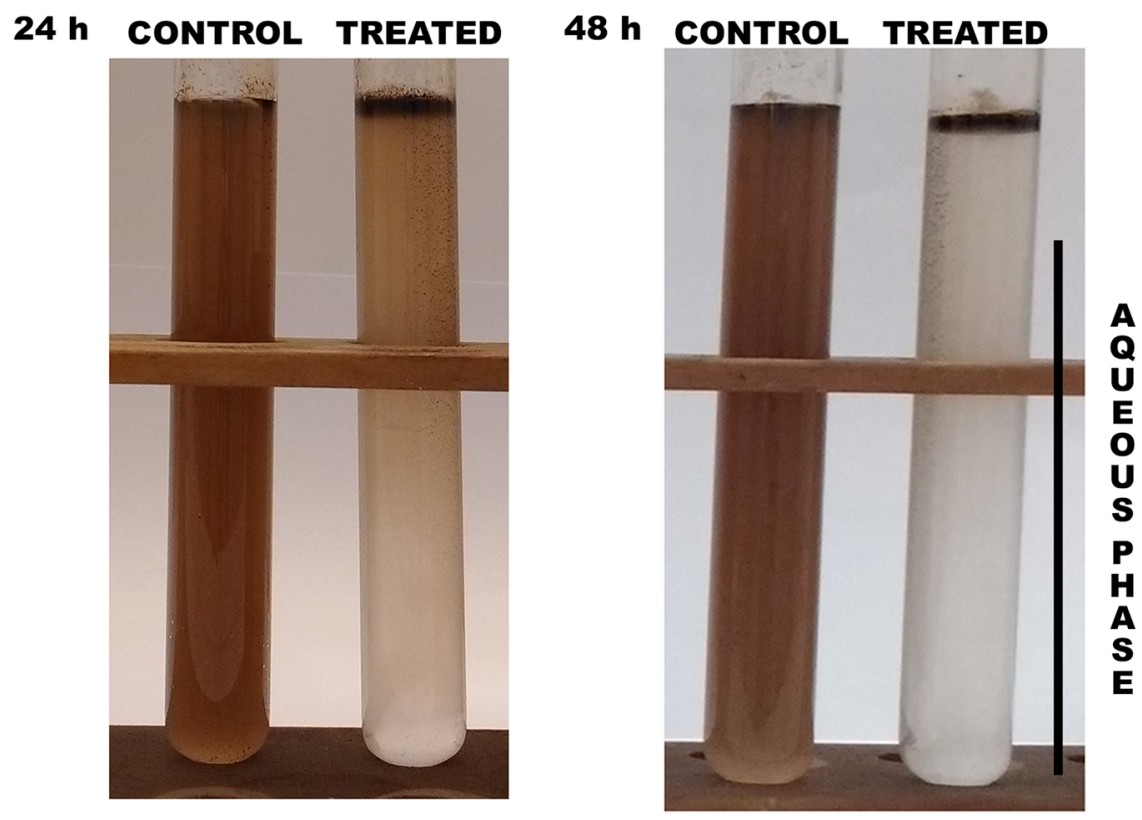

\section{b CONTROL}

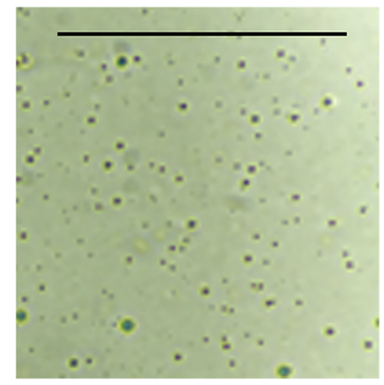

TREATED
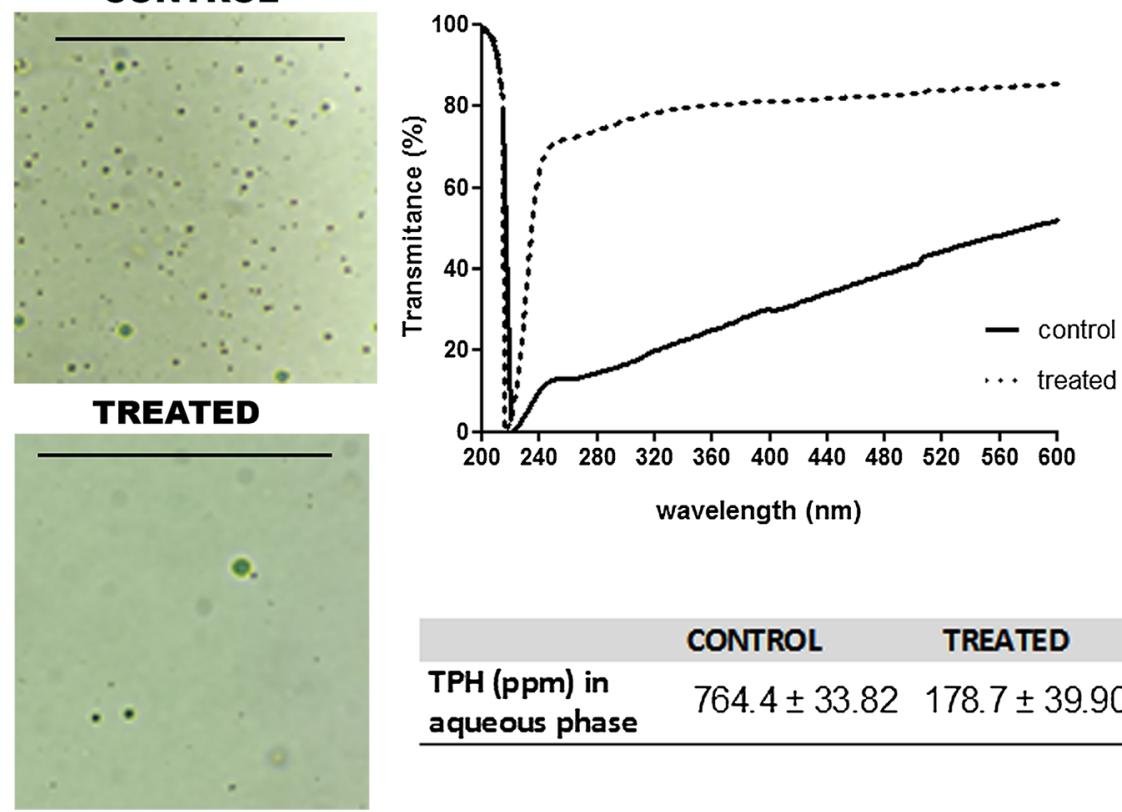

\begin{tabular}{llc} 
& CONTROL & TREATED \\
$\begin{array}{ll}\text { TPH (ppm) in } \\
\text { aqueous phase }\end{array}$ & $764.4 \pm 33.82$ & $178.7 \pm 39.90^{*}$ \\
\hline
\end{tabular}

Fig. 1 Demulsification of IMO emulsion by a microbial indigenous consortium. The consortium was grown in MS with $0.25 \%(\mathrm{v} / \mathrm{v})$ of bilge oil phase as the only carbon and energy source. a A sample of $2 \mathrm{~mL}$ was taken and placed in $15 \mathrm{~mL}$ of IMO emulsion and left undisturbed $24 \mathrm{~h}$ or $48 \mathrm{~h}$. b The aqueous phase of the control and treated tubes after $48 \mathrm{~h}$ of demulsification was taken and microscopic images (Bar: $0.05 \mathrm{~mm}$ ), transmittance spectrum and TPH levels were obtained. Star indicates a significant difference with respect to the control at $p<0.01$ (t-test) 
(Online Resource 2) and after $48 \mathrm{~h}$, a larger average droplets size was observed (control: $0.93 \pm 0.02 \mu \mathrm{m}$; treated: $2.72 \pm 0.10 \mu \mathrm{m}$; t-test at $P<0.01$ ).

This is the first report where a consortium of native bilge microorganisms with demulsifying ability was enriched and studied, being of great interest to generate new tools for treating the problematic emulsions of this waste. The study of native microbial consortium for biological treatment of wastes would bring advantages on non-native and pure microbes, since they are adapted to this complex toxic residue and can act synergistically (Gouveia et al. 2018). Our microbial consortium also grows at the expense of oily bilge residue as the sole source of carbon and energy (Fig. 2a), which is another interesting feature to be used in the treatment of these wastes. While demulsifying microorganisms have been isolated from HC different contaminated sites (Das et al. 2001; Li et al. 2012; Coutinho et al. 2013; Cai et al. 2014), it remains to be established whether there is a real relationship between the ability to degrade $\mathrm{HC}$ and demulsify ( $\mathrm{Li}$ et al. 2017). Rather, biodegradation has been
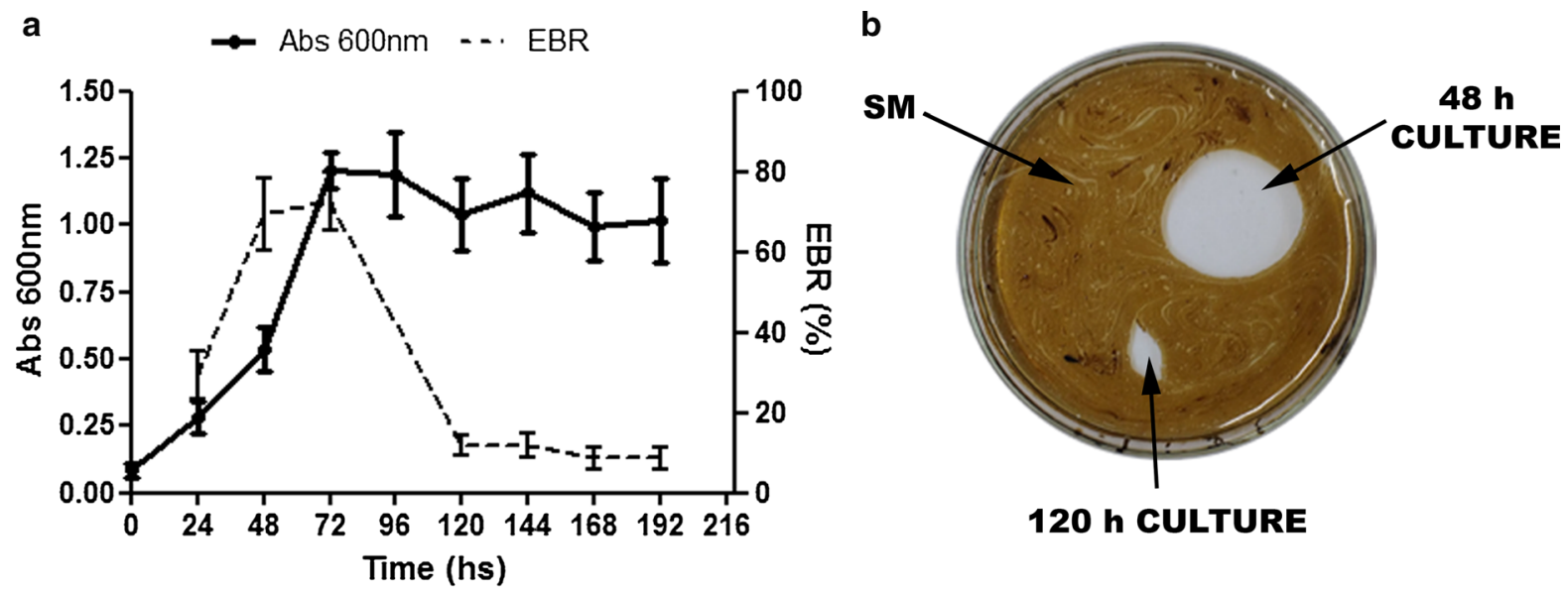

C
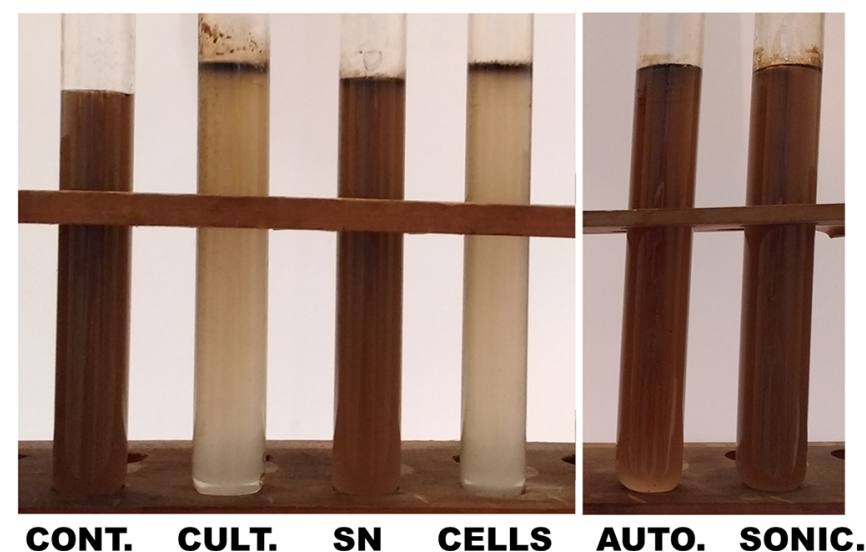

d

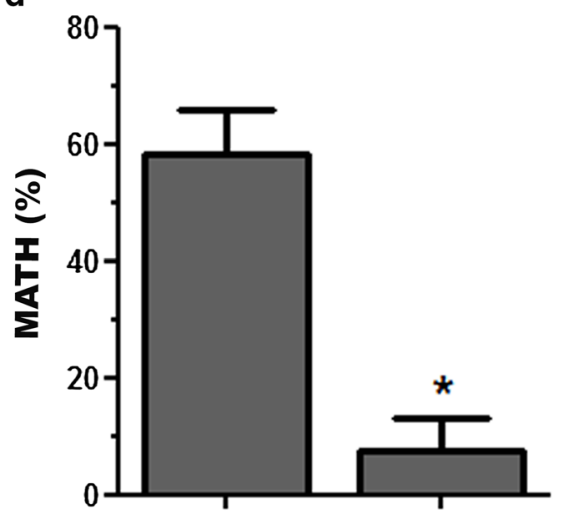

EXPONENTIAL STATIONARY

Fig. 2 Consortium growth curve and demulsifying ability. The consortium was grown in MS with $0.25 \%$ (v/v) of bilge oil phase as the only carbon and energy source. a The microbial growth was analyzed by $\mathrm{DO}_{600 \mathrm{~nm}}$ measurement and the demulsifying ability by bottle test employing $15 \mathrm{~mL}$ IMO emulsion $+2 \mathrm{~mL}$ MS (control) or culture. Average and SD of three independent experiments are shown. b Oil spreading test employing $50 \mu \mathrm{L}$ of MS (control), $50 \mu \mathrm{L}$ of $48 \mathrm{~h}$ or $120 \mathrm{~h}$ culture. c Two mL sample of $72 \mathrm{~h}$ old culture or MS (cont., control) was taken and the demulsifying activity of the culture (cult.), the pelleted cells (resuspended in MS) (cells), the supernatant (SN) of a centrifugation ( $9000 \mathrm{~g}$ for $10 \mathrm{~min}$ ), or the culture autocleaved (auto.) or sonicated (sonic.) was evaluated. A representative image of three independent experiments is shown. d MATH values (\%) obtained in exponential and stationary growth phase. Stars indicate a significant difference with respect to the control at $p<0.01$ (t-test) 
associated with the emulsification of HC (Mnif et al. 2011; Das and Chandran 2011). In this regard, it could be an interesting field to explore, and our studies will continue in order to contribute with this knowledge.

Effect of culture age and localization of the demulsifying activity

The demulsifying ability of the microbial consortium in the different phases of growth was tested. Figure $2 \mathrm{a}$ shows the growth of the consortium in MS with $0.25 \%$ bilge oil phase as the only carbon and energy source. The highest demulsification capacity was observed during the exponential growth phase, with an average EBR of $70.96 \pm 2.42 \%$ with 48 and $72 \mathrm{~h}$ culture. In the stationary phase, the demulsification capacity was significantly lower with an average EBR of $10.23 \pm 1.92 \%$ with 120 and $192 \mathrm{~h}$ culture (t-test at $p<0.01$ ), still having increased the concentration of cells used in the bottle tests from approximately $1 \times 10^{8}$ cell $/ \mathrm{mL}$ of emulsion to $4 \times 10^{8}$ cell $/ \mathrm{mL}$ (data not shown). The oil spreading test confirms this result (Fig. 2b), observing a greater displacement of crude oil in the presence of cultures in exponential growth phase than with cultures in stationary growth phase.

To determine if the demulsifier is cell wall associated or free extracellular, culture samples were taken at different times during microbial growth and the demulsifying activity of the pelleted cells or the supernatant was evaluated. Figure $2 \mathrm{c}$ shows a representative image of the results obtained with culture of 24, 48 and $72 \mathrm{~h}$ of growth. Demulsifying ability was observed in the presence of cells and not in supernatants, indicating that, as in several species (Huang et al. 2012; Liu et al. 2011; Mohebali el al. 2012), it is cell wall-bound. The cell wall-bound biodemulsifiers identified so far include proteins (Liu et al. 2011; Hou et al. 2014), mycolic acid (Ma et al. 2006), and fatty acid components (Huang et al. 2012), or composite substances such as protein-lipid- carbohydrate (Huang et al. 2013). Our consortium could include one or more demulsifying microorganisms with any of the components mentioned. In this microbial consortium, autoclaved or sonicated cells lose the ability to demulsify (Fig. 2c), indicating that cellular integrity is necessary. These results are in agreement with Nadarajah et al. (2002), who observed that autoclaving the microbial culture completely destroys its demulsifying ability.
The ability of a demulsifier to absorb to an oilwater interface is crucial to its demulsifying activity. This process can be affected by cell surface hydrophobicity and hydrophobic-hydrophilic balance of the cell wall, when the demulsifying activity is linked to the cell surface (Liu et al. 2011; Coutinho et al. 2013; Huang et al. 2013). Most demulsifying bacteria have high values of cellular hydrophobicity, indicating a positive relationship between hydrophobicity and demulsifying ability (Sabati and Motamedi 2018). The same was observed in this work, where the highest values of microbial adhesion to HC (MATH values: $58.28 \pm 3.46 \%$ ) were obtained with cells in exponential growth phase (Fig. 2d), when the highest EBR were obtained (Fig. 2a).

\section{Effect of culture concentration}

Demulsification using different quantities of cells was evaluated with $72 \mathrm{~h}$ old culture samples. The demulsification activity increased with the increase in cell concentration used in the assay. The highest activity was obtained in tests with $1 \times 10^{8}$ cells $/ \mathrm{mL}$ where maximum efficiency was achieved (Fig. 3a, b). Higher cell concentrations assayed showed similar efficiency. Coutinho et al. (2013) observed an increase in the demulsifying activity of Pseudomonas aeruginosa MSJ when using 20 to $60 \mathrm{mg}$ of cells, while from $60 \mathrm{mg}$ of cells the demulsifying activity decreased. Das (2001) used cells of Micrococcus sp. and observed that increasing the cellular concentration from 2 to $4 \mathrm{mg} / \mathrm{mL}$, the half-life of an $\mathrm{O} / \mathrm{W}$ emulsion was significantly reduced. A positive correlation between the percent demulsification and the concentration of cells was also observed by Park et al. (2000) and Nadarajah et al. (2002). Considering an average bacterial cell weight of $1 \times 10^{-12} \mathrm{~g}$ (Malke et al. 1982), we have used $0.1 \mathrm{mg}$ cell $/ \mathrm{mL}$, a lower cell concentration compared to other studies; however due to the different characteristics of emulsions, quantitative comparisons should not be made.

\section{Demulsification in agitation and effect of assay incubation temperature}

The demulsification studies with the bottle test are done under static conditions. Studying the demulsification of bilge emulsions in motion is of great interest considering the potential use of the biodemulsifiers in 


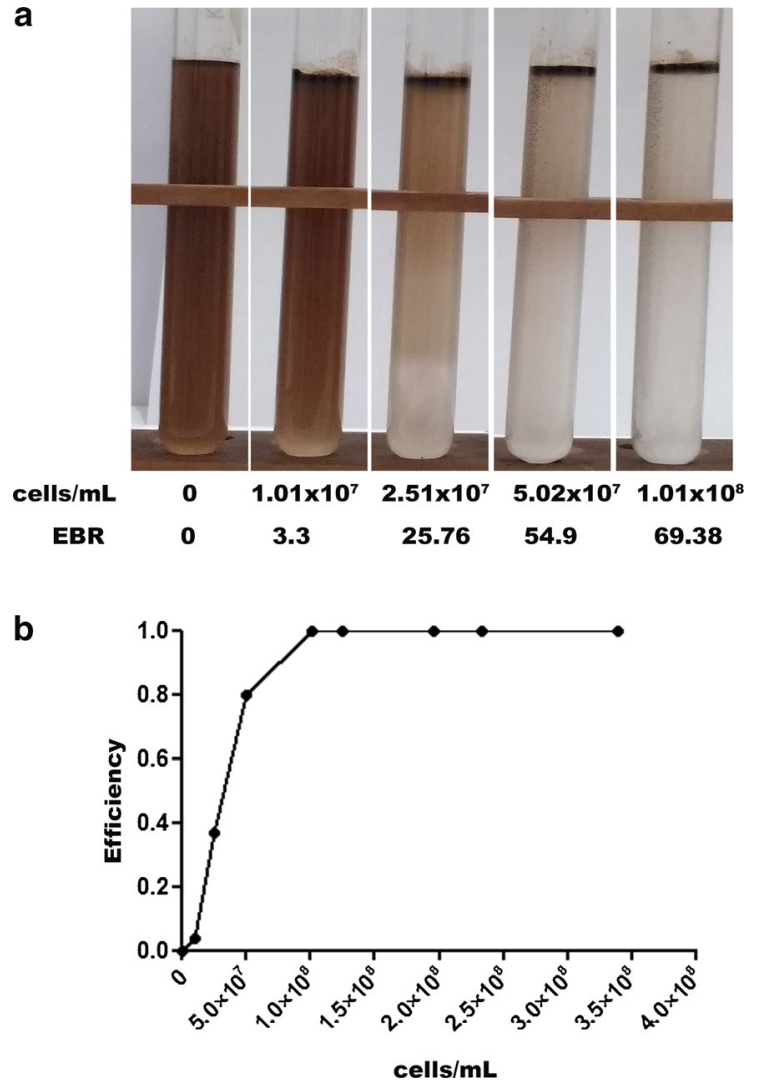

Fig. 3 Effect of culture concentration on demulsification. The consortium was grown in MS with $0.25 \%$ (v/v) of bilge oil phase as the sole source of carbon and energy. Two $\mathrm{mL}$ of MS (control) o MS containing different quantity of cell of $72 \mathrm{~h}$ old culture were placed in tube tests containing $15 \mathrm{~mL}$ of IMO emulsion. The demulsification activity was evaluated and a a photography of a representative assay after $48 \mathrm{~h}$ of rest is shown. b Effectiveness of demulsification in function of cell concentration

treatments on board the ships. To evaluate this, the bottle test was done in orbital $(150 \mathrm{rpm})$ and reciprocal (back-and-forth) (65 rpm) agitation. Interestingly, the results showed that, in both conditions of agitation, the EBR were similar to that of the static condition (Table 1, Tukey-test at $p<0.01$ ).

It is known that heat favors the separation of emulsions and many publications perform the bottle tests at temperatures as $35{ }^{\circ} \mathrm{C}, 50{ }^{\circ} \mathrm{C}$ and $75{ }^{\circ} \mathrm{C}$ (Nadarajah et al. 2002; Amirabadi et al. 2013; Coutinho et al. 2013; Cai et al. 2019). The assays described above in this work were done at $25{ }^{\circ} \mathrm{C}$, but also we analyze whether the consortium has the ability to demulsify at $4{ }^{\circ} \mathrm{C}$ and $12{ }^{\circ} \mathrm{C}$, which are common temperatures of the surface seawater. The results
Table 1 Demulsification with tubes under agitation or under different incubation temperatures

\begin{tabular}{ll}
\hline Test & EBR \\
\hline $25{ }^{\circ} \mathrm{C}$ & $71.66 \pm 7.12 a$ \\
$25{ }^{\circ} \mathrm{C}$ orbital & $72.8 \pm 9.6 a$ \\
$25{ }^{\circ} \mathrm{C}$ reciprocal & $70.9 \pm 7.6 a$ \\
$4{ }^{\circ} \mathrm{C}$ & $33.5 \pm 3.6 \mathrm{~b}$ \\
$12{ }^{\circ} \mathrm{C}$ & $35.61 \pm 3.9 \mathrm{~b}$ \\
\hline
\end{tabular}

25-12-4 ${ }^{\circ} \mathrm{C}$ : incubation in static conditions

$25{ }^{\circ} \mathrm{C}$ orbital or reciprocal: incubation in orbital or seesaw motion

Different letters indicates significant difference between them at $p<0.01$ (Tukey-test)

showed EBR around $33-35 \%$ at $4{ }^{\circ} \mathrm{C}$ and $12{ }^{\circ} \mathrm{C}$ (Table 1). Although they are significantly lower than EBR of $71.66 \%$ obtained at $25{ }^{\circ} \mathrm{C}$ (Tukey-test at $p<0.01$ ), it is interesting to highlight the flexibility of the microbial consortium to act at low temperatures.

Demulsification of real bilge wastewater samples

Several studies have demonstrated the great variability in the composition of bilge wastewater between different vessels (reviewed in Church et al. 2019). Large variations in the levels of total suspended solids, chemical oxygen demand and oil and grease concentration have been observed. Bilge wastewater contains a diverse set of cleaners and detergents used in different shipboard activities. Therefore, the types of surfactants in bilge wastewater are largely dependent on shipboard activities, which can change daily (Church et al. 2019). Oily liquid waste treatment based on microbial processes tends to be less expensive; however, the microorganisms could die or lose abilities under hostile and variable conditions. To test the ability of the microbial consortium to demulsify different bilge wastewater, bilge water emulsions were prepared by mixing aqueous phase and oily phase of wastewater bilge samples (non sterile) from different vessels (deep sea fishing ship, dredge ship, oceanographic ship and coastal fishing boats). Figure 4 shows that the consortium was able to demulsify the different bilge water emulsions, indicating the good microbial resilience and demulsifying activity of the consortium. Further studies are needed to control and improve the 
a

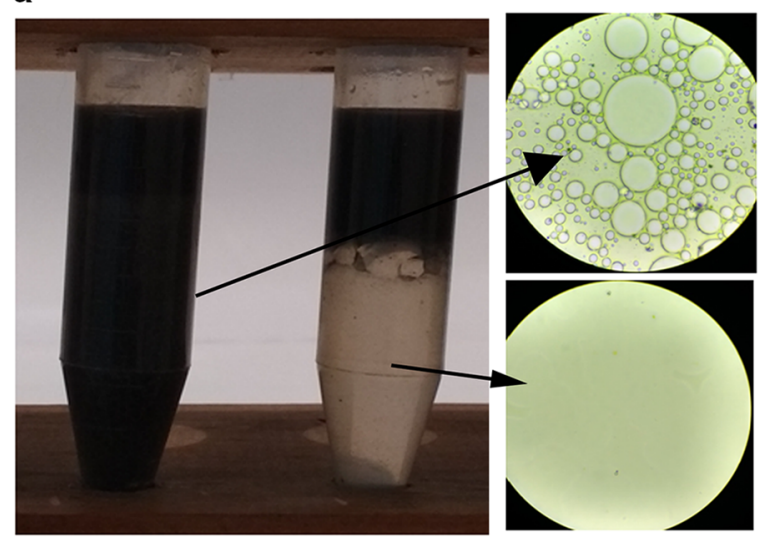

C

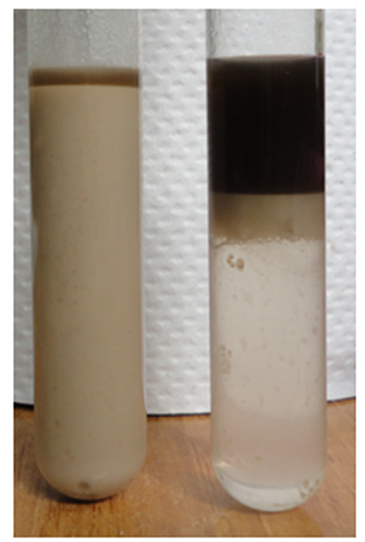

b

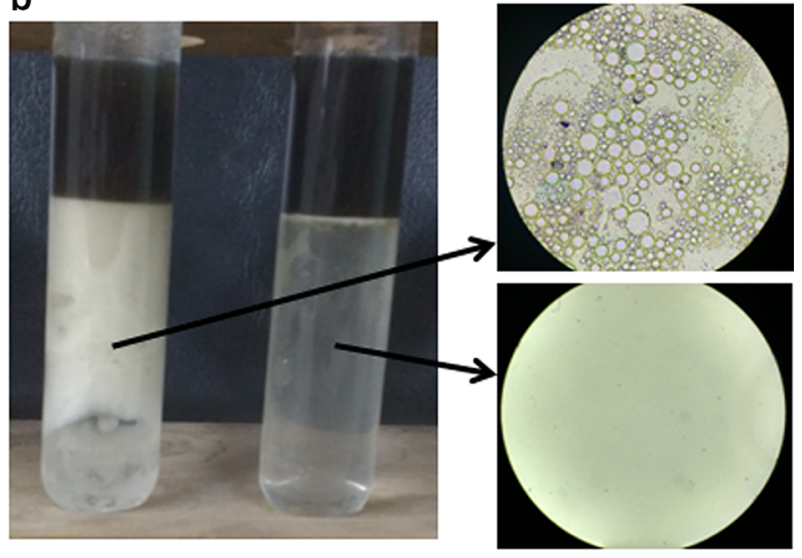

e

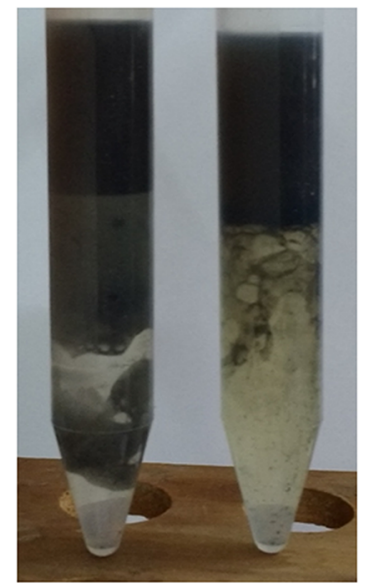

Fig. 4 Demulsification of oil bilge water emulsions. The consortium was grown in MS with $0.25 \%$ (v/v) of bilge oil phase as the sole source of carbon and energy. Two mL of MS (control, left tube of each photograph) or $2 \mathrm{~mL}$ of seventy h old culture (in exponential growth phase, right tube of each photograph) were taken and the demulsifying activity was evaluated by the bottle test employing as emulsions: a $3 \mathrm{~mL}$ oil phase $+2 \mathrm{~mL}$

\section{system response to external disturbances} such as quality and quantity fluctuation in wastewaters.

\section{Consortium microbiome composition}

In the present study we determined the composition of the microbial consortium which has shown a stable demulsifying activity and growth by analyzing 16S rRNA gene Illumina amplicon sequencing targeting the hypervariable region V4. A total of 110,226 pair-end high quality assembled reads of $300 \mathrm{bp}$ were obtained. The Operational Taxonomic Groups (OTUs) water phase of OBW from fishing boat; $\mathbf{b} 3 \mathrm{~mL}$ of oily phase of dredge boat $+6 \mathrm{~mL}$ water phase from fishing boat, $\mathbf{c} 2 \mathrm{~mL}$ of oily phase of dredge boat $+1 \mathrm{~mL}$ of fresh water, $\mathbf{d} 3 \mathrm{~mL}$ oil phase $+2 \mathrm{~mL}$ water phase of OBW from deep sea fishing ship. e $5 \mathrm{~mL}$ of oily phase of oceanographic boat $+5 \mathrm{~mL}$ water phase oceanographic boat. a, b Representative microphotographs of the sections indicated by arrows are shown

at a $3 \%$ distance were 879.4 OTUs (Fig. 5). The calculated Good's coverage of $99.7 \%$ indicated that the sequence complexity of the amplicon has been described near completion, thus the inferred composition represents the relative types and abundances in the consortium. A Simpson index of 0.931 indicates the presence of highly predominant OTUs, while Shannon index of 4.9 indicates that the richness and evenness of the bacterial composition are both high.

Given that the microbial consortium was isolated from bilge liquid samples of marine ships and cultivated using sterile seawater (supplemented with $\mathrm{N}$ source) and bilge oily phase as the sole source of 


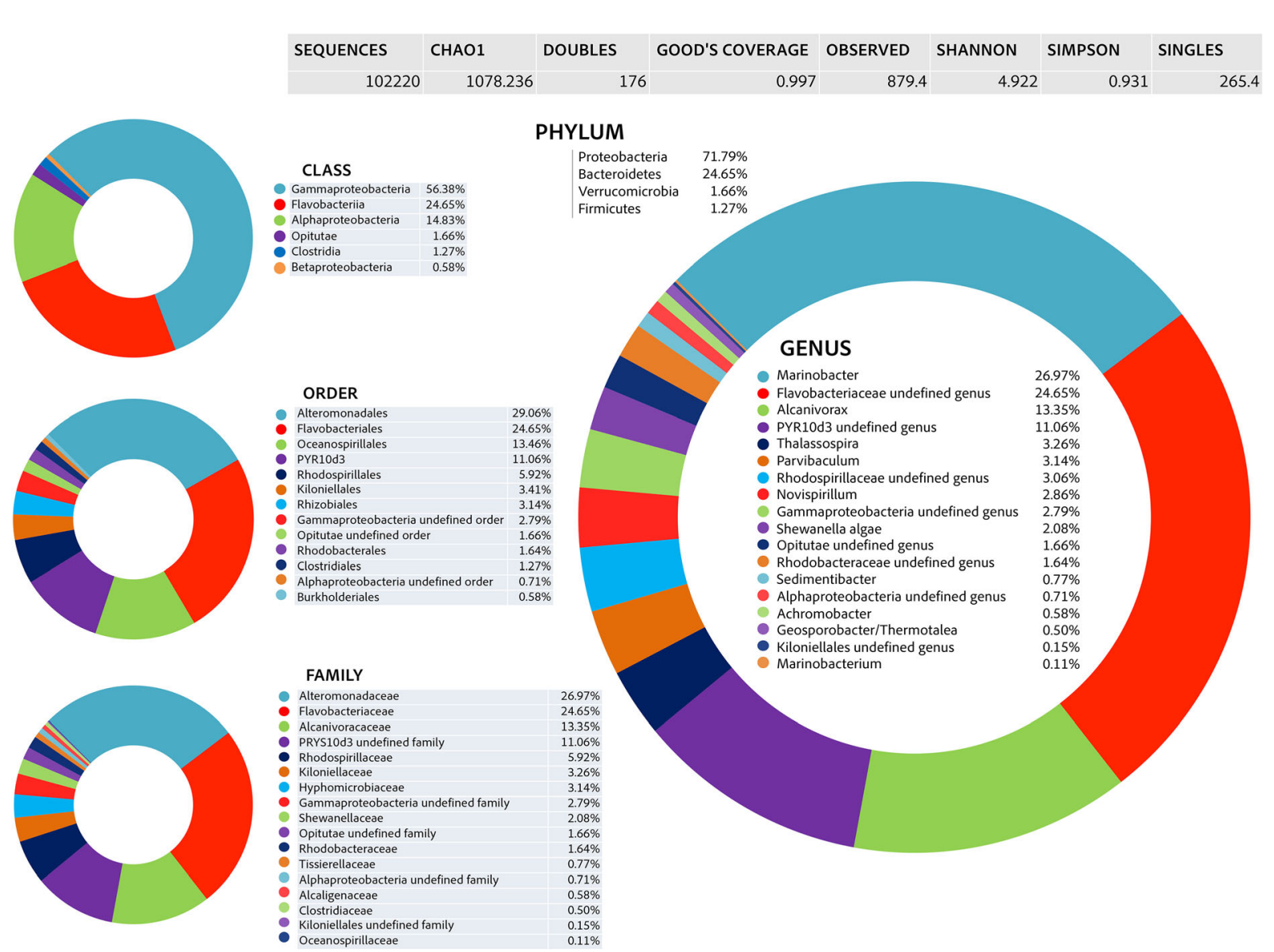

Fig. 5 Bacterial members and relative abundance in the demulsifier microbial consortium emerging from bilge wastewater. Bacterial and archaeal community composition with a relative frequency of reads sharing same taxa classification in $16 \mathrm{~S}$ rRNA gen amplicon Illumina sequencing from total DNA extracts of the composite homogenized demulsifier microbial

carbon and energy, the members of the consortium are expected to be marine microorganisms and $\mathrm{HC}$ degraders. The obtained results are in agreement with this expected microbial assemblage (Fig. 5). The most abundant bacterial types detected by this approach are classified as Marinobacter spp. with $27 \%$ of relative abundance, Flavobacteriaceae with $24.6 \%$, Alcanivorax spp. with $13.3 \%$ and Gammaproteobacteria PYR1Od3 with $11.1 \%$, followed by Thalassospira spp. and Parvibaculum spp. among others. All of them are bacterial types comprising several reported strains with capability to degrade oil contaminants in the environment and in vitro culturing conditions (Deppe et al. 2005; Margareth et al. 2006; Singleton et al. 2006; Duran 2010; Rosario-passapera et al. 2012;

consortium. Maximum resolution of taxonomic classifications with RDP Naïve Bayesian Classifier with a confidence threshold value $>80 \%$ are labeled with the corresponding class, family, order, genus, specie taxa names. The complete OTU identifiers and sequence dataset can be found as Online Resource 1

Warr et al. 2018; Chaudhary and Kim 2018). Our study is providing evidences and suggesting that this assemblage of bacterial predominant types is collectively producing a remarkable demulsification activity. While they had been reported in other studies as important hydrocarbonoclastic bacteria, copio or oligotrophs found in marine sediments or in water columns, usually linked to hydrocarbon contamination events, isolated strains of Marinobacter and Alcanivorax had not been studied regarding their demulsifying capabilities. The demulsifying cultured microorganisms described so far that had been isolated from oil contaminated places include members such as Alcaligenes sp., Micrococcus sp., Rhodococcus sp., Ochrobactrumanthopi, Pseudomonas aeruginosa, 
Streptomyces and Bacillus (reviewed in Zolfaghari et al. 2016). Our work suggests that there are not-yet cultured types classified inside the Flavobacteriaceae family and the Gammaproteobacteria order PYR10d3 that could be maintained in the microbial guild which may encode or contribute to the demulsifying activity detected. Thallasospira sp. and Parvibacullum sp. could also contribute to biodemulsification, since some strains of these genera are surfactant degraders (Dong et al. 2004; Bassey and Grigson 2011). Cai et al. (2019), reported thirty-seven marine O/W emulsion demulsifying bacterial strains belonging to five genera (Bacillus, Pseudomonas, Rhodoccocus, Halomonas, Acinetobacter) and fifteen species. In the consortium described in this work, twelve OTUs were found belonging to the genus Pseudomonas, seven to Halomonas, three to Acinetobacter and one to Bacillus. Although these genera are detected in very low abundance $(<0.01 \%)$ in the consortium analyzed and could have some role in the demulsification of emulsions, given the remarkable demulsifying activity detected, the organisms in higher cell density are probably responsible of the majority of the effect observed. The microbiome consortium is composed of reported predominant bacterial types that have as common traits, the ability to thrive, resist and degrade HC. In addition, some strains are capable of producing biosurfactants with emulsifying activities (Bodour et al. 2004; Antoniou et al. 2015; Raddadi et al. 2017; Zenati et al. 2018). Our findings also allowed us to provide some insights regarding the possible double role of the biosurfactant producing organisms that seems to play both, emulsifying and demulsifying activities in petroleum hydrocarbon contaminants in the environment, depending of the bioavailability, phase dispersion and limiting conditions for bacterial growth on which the specific targeted contaminant is found. This is certainly an aspect to be explored in detail in further evaluations and assays of demulsified and emulsified $\mathrm{HC}$ tests for biosurfactant production coupled to HC biodegradation. This will expand the set of know synergistic microbial mechanisms for $\mathrm{HC}$ bioremediation treatments of emulsified contaminants in the marine environment such as by enriched autochthonous microbial consortia sequential screenings rationally selected for the most relevant activities to achieve efficient, sustained and sustainable bioremediation processes.

\section{Conclusions}

Research on biodemulsification has primarily focused on water-in-oil emulsions, which are commonly present in waste oil sludge. Biological demulsification of oil-in-water emulsions is still at a preliminary stage and demulsifying microbes are mostly of terrestrial origin. The challenge in bilge wastewater treatment lies in the presence of stable oil-in-water emulsions, which renders traditional treatment methods less effective, and demulsification is required. In this work, a microbial demulsifying consortium of oil in water emulsion of bilge wastewater was enriched from marine ship bilge samples, using oily phase of bilge residue as the sole carbon source. This is the first demulsifying microbial consortium enriched and characterized from bilge wastewater. Its demulsifying ability was associated with exponentially growing cells in positive association with high values of cell adhesion to HC. There was a positive relationship between cell concentration and demulsifying ability until reaching a concentration where the efficiency remained at its maximum value. The consortium showed an interesting ability to demulsify at different temperatures, conditions of agitation, and bilge emulsions from different vessels, which vary in physicochemical and biological composition. These abilities are of great interest for possible future applications of the consortium on board bilge wastewater treatment. The Bacterial and Archaeal consortium composition was analyzed by Illumina 16S rRNA gene sequencing technology, revealing a well-defined assemblage of microorganisms with members that have previously been associated with $\mathrm{HC}$ degradation and some with demulsification processes, including bacterial types that do not have a closer representative species described in pure cultures. This promising result suggests that the consortium retrieved and enriched by our approach from the oily bilge wastewaters, a poorly studied and highly toxic waste could be a novel bioresource to understand, propose and develop biological demulsification processing of oily waters as a highly effective and environmentally friendly technological option.

Acknowledgements We would like to thank to "Consejo Nacional de Investigaciones Científicas y Técnicas (CONICET), Comisión de Investigaciones Científicas de la Provincia de Buenos Aires (CIC)", and "Universidad Nacional 
de Mar del Plata" for grants and researchers salaries. HJ and MVP would like to thank Dr. Erika Garcia-Bonilla (Microbiomas Foundation) and Ericsson Coy (InquiBio, UMNG) for providing outstanding experimental, analytical and infrastructure support. This project was partially supported by VT38-UNMdP10982 and PIT-AP-BA-2016.

\section{References}

Adilbekova AO, Omarova KI, Karakulova A, Musabekov KB (2015) Colloids and surfaces A : physicochemical and engineering aspects nonionic surfactants based on polyoxyalkylated copolymers used as demulsifying agents. Colloids Surf A Physicochem Eng Asp 480:433-438. https://doi.org/10.1016/j.colsurfa.2014.11.004

Al-sabagh AM, Kandile NG, El-ghazawy RA, El-din MRN (2011) Synthesis and evaluation of some new demulsifiers based on bisphenols for treating water-in-crude oil emulsions. Egypt J Pet 20:67-77. https://doi.org/10.1016/j.ejpe. 2011.06.008

Amirabadi SS, Jahanmiri A, Rahimpour MR et al (2013) Investigation of Paenibacillus alvei ARN63 ability for biodemulsifier production: medium optimization to break heavy crude oil emulsion. Colloids Surf B Biointerfaces 109:244-252. https://doi.org/10.1016/j.colsurfb.2013.03. 029

Antoniou E, Fodelianakis S, Korkakaki E, Kalogerakis N (2015) Biosurfactant production from marine hydrocarbon-degrading consortia and pure bacterial strains using crude oil as carbon source. Front Microbiol 6:274. https://doi.org/10. 3389/fmicb.2015.00274

Bassey DE, Grigson SJW (2011) Degradation of benzyldimethyl hexadecylammonium chloride by Bacillus niabensis and Thalassospira sp. isolated from marine sediments. Toxicol Environ Chem 93:44-56. https://doi.org/ 10.1080/02772248.2010.504357

Bodour AA, Guerrero-barajas C, Jiorle BV et al (2004) Structure and characterization of flavolipids, a novel class of biosurfactants produced by Flavobacterium sp. strain MTN11. Appl Env Microbiol 70:114-120. https://doi.org/10.1128/ AEM.70.1.114

Cai Q, Zhang B, Chen B et al (2014) Screening of biosurfactant producers from petroleum hydrocarbon contaminated sources in cold marine environments. Mar Pollut Bull 86:402-410. https://doi.org/10.1016/j.marpolbul.2014.06. 039

Cai Q, Zhu Z, Chen B, Zhang B (2019) Oil-in-water emulsion breaking marine bacteria for demulsifying oily wastewater. Water Res 149:292-301. https://doi.org/10.1016/j.watres. 2018.11.023

Caplan JA, Newton C, Kelemen D (2000) Technical report: novel oil/water separator for treatment of oily bilgewater. Mar Technol 37:111-115

Caporaso JG, Kuczynski J, Stombaugh J et al (2010) QIIME allows analysis of high- throughput community sequencing data Intensity normalization improves color calling in SOLiD sequencing. Nat Methods 7:335-433. https://doi. org/10.1038/nmeth.f.303
Cengel JA, Knudsen JG, Landsberg A, Faruqui AA (1961) An apparatus for the measurements of light transmittance of emulsions. Can J Chem Eng 39:189-191. https://doi.org/ 10.1002/cjce. 5450390503

Chaudhary DK, Kim J (2018) Flavobacterium naphthae sp. nov., isolated from oil-contaminated soil. Int $\mathbf{J}$ Syst Evol Microbiol 68(1):305-309

Church J, Lundin JG, Diaz D et al (2019) Identification and characterization of bilgewater emulsions. Sci Total Environ 691:981-995. https://doi.org/10.1016/j.scitotenv.2019. 06.510

Coutinho JOPA, Silva MPS, Moraes PM et al (2013) Demulsifying properties of extracellular products and cells of Pseudomonas aeruginosa MSJ isolated from petroleumcontaminated soil. Bioresour Technol 128:646-654. https://doi.org/10.1016/j.biortech.2012.09.137

Das M (2001) Characterization of de-emulsication capabilities of a micrococcus species. Bioresour Technol 79:15-22. https://doi.org/10.1016/s0960-8524(01)00039-6

Das N, Chandran P (2011) Microbial degradation of petroleum hydrocarbon contaminants: an overview. Biotechnol Res Int 2011:941810. https://doi.org/10.4061/2011/941810

Deppe U, Richnow H, Michaelis W, Antranikian G (2005) Degradation of crude oil by an arctic microbial consortium. Extremophiles 9:461-470. https://doi.org/10.1007/ s00792-005-0463-2

Dong W, Eichhorn P, Radajewski S et al (2004) Parvibaculum lavamentivorans converts linear alkylbenzenesulphonate surfactant to sulphophenylcarboxylates, a, b-unsaturated sulphophenylcarboxylates and sulphophenyldicarboxylates, which are degraded in communities. J Appl Microbiol 96:630-640. https://doi.org/10.1111/j.1365-2672. 2004.02200.x

Duran R (2010) Marinobacter. In: Timmis KN (ed) Handbook of Hydrocarbon and Lipid Microbiology. Springer, Berlin, Heidelberg, pp 1725-1735

EPA (2011) Oily bilgewater separators: office of wastewater management. U.S. Environmental Protection Agency, Washington D.C. EPA 800-R-11-007

García-Bonilla E, Brandão PF, Pérez T, Junca H (2019) Stable and enriched cenarchaeum symbiosum and uncultured betaproteobacteria HF1 in the microbiome of the Mediterranean sponge Haliclonafulva (Demospongiae: Haplosclerida). Microb Ecol 77:25-36

GESAMP (IMO/FAO/UNESCO-IOC/UNIDO/WMO/IAEA/ UN/UNEP Joint group of experts on the scientific aspectsof marine environmental protection) (2007) Estimates of oil entering the marine environment from sea-based activities. Rep Stud GESAMP No 75 GESAMP 96

Gouveia V, Almeida CMR, Almeida T et al (2018) Indigenous microbial communities along the NW Portuguese Coast: potential for hydrocarbons degradation and relation with sediment contamination. Mar Pollut Bull 131:620-632. https://doi.org/10.1016/j.marpolbul.2018.04.063

Hou N, Li D, Ma F et al (2014) Effective biodemulsifier components secreted by Bacillus mojavensis $\mathrm{XH}-1$ and analysis of the demulsification process. Biodegradation 25:529-541. https://doi.org/10.1007/s10532-013-9679-5

Huang X, Li M, Lu L et al (2012) Relationship of cell-wall bound fatty acids and the demulsification efficiency of demulsifying bacteria Alcaligenes sp. S-XJ-1 cultured with 
vegetable oils. Bioresour Technol 104:530-536. https:// doi.org/10.1016/j.biortech.2011.10.034

Huang X, Peng K, Feng Y et al (2013) Separation and characterization of effective demulsifying substances from surface of Alcaligenes sp. S-XJ-1 and its application in waterin-kerosene emulsion. Bioresour Technol 139:257-264. https://doi.org/10.1016/j.biortech.2013.04.043

Huang XF, Guan W, Liu J et al (2010) Characterization and phylogenetic analysis of biodemulsifier-producing bacteria. Bioresour Technol 101:317-323. https://doi.org/10. 1016/j.biortech.2009.07.086

IMO (1988) International convention for the prevention of pollution from ships (MARPOL). Annex $V$ prevention of pollution by garbage from ships

Issaka SA (2015) Review on the fundamental aspects of petroleum oil emulsions and techniques of demulsification. J Pet Environ Biotechnol 6:214. https://doi.org/10.4172/21577463.1000214

Kang W, Yin X, Yang H, et al (2018) Demulsification performance, behavior and mechanism of different demulsifiers on the light crude oil emulsions. 545:197-204. https://doi. org/10.1016/j.colsurfa.2018.02.055

Kokal SL (2005) Crude oil emulsions: a state-of-the-art review. SPE Prod Facil 20:5-13. https://doi.org/10.2118/77497PA

Koss L (1996) Technology development for environmentally sound ships of the 21 st century: an international perspective. J Mar Sci Technol 1:127-137. https://doi.org/10. 1007/BF02391173

Lee JC, Lee KY (2000) Emulsification using environmental compatible emulsifiers and de-emulsification using D.C. field and immobilized Nocardia amarae. Biotechnol Lett 22:1157-1163. https://doi.org/10.1023/A:1005601525934

Li C, Jia T, Fu M et al (2017) Biodemulsifiers produced by Achromobacter sp. and their features in improving the biodegradation of phenanthrene. RSC Adv 7:4339-4347. https://doi.org/10.1039/c6ra25167f

Li X, Li A, Liu C et al (2012) Characterization of the extracellular biodemulsifier of Bacillus mojavensis XH1 and the enhancement of demulsifying efficiency by optimization of the production medium composition. Process Biochem 47:626-634. https://doi.org/10.1016/j.procbio.2012.01. 004

Liu J, Huang XF, Lu LJ et al (2010) Optimization of biodemulsifier production from Alcaligenes sp. S-XJ-1 and its application in breaking crude oil emulsion. J Hazard Mater 183:466-473. https://doi.org/10.1016/j.jhazmat. 2010.07.047

Liu J, Lu L, Huang X et al (2011) Relationship between surface physicochemical properties and its demulsifying ability of an alkaliphilic strain of Alcaligenes sp S-XJ-1. Process Biochem 46:1456-1461. https://doi.org/10.1016/j.procbio. 2011.03.018

Ma T, Liang F, Xi Y, Liu R (2006) Performance of demulsification by Rhodococcus sp. PR-1. Environ Sci 27:1191-1196

Malke H, Davis BD, Dulbecco R, et al (1982) Microbiology (3rd Edition).. 1355 S., ca. 1300 Abb., ca. 150 Tab. Hagerstown 1980. Harper \& Row Publishers. DFL 65.00. Z Allg Mikrobiol, 22: 279-279. doi:10.1002/jobm.19820220411
Margareth E, Brito S, Guyoneaud R, Goñi-urriza M (2006) Characterization of hydrocarbonoclastic bacterial communities from mangrove sediments in Guanabara Bay, Brazil. Res Microbiol 157:752-762. https://doi.org/10. 1016/j.resmic.2006.03.005

Mnif S, Chamkha M, Labat M, Sayadi S (2011) Simultaneous hydrocarbon biodegradation and biosurfactant production by oilfield-selected bacteria. J Appl Microbiol 111:525-536. https://doi.org/10.1111/j.1365-2672.2011. 05071.x

Mohebali G, Kaytash A, Etemadi N (2012) Efficient breaking of water/oil emulsions by a newly isolated de-emulsifying bacterium, Ochrobactrum anthropi strain RIPI5-1. Colloids Surf B Biointerfaces 98:120-128. https://doi.org/10.1016/ j.colsurfb.2012.04.037

Nadarajah N, Singh A, Ward OP (2002) De-emulsification of petroleum oil emulsion by a mixed bacterial culture. Process Biochem 37:1135-1141. https://doi.org/10.1016/ S0032-9592(01)00325-9

National Research Council (NRC) (2003) Oil in the sea III: inputs, fates, and effects. The National Academies Press, Washington

Nievas ML, Commendatore MG, Olivera NL et al (2006) Biodegradation of bilge waste from Patagonia with an indigenous microbial community. Bioresour Technol 97:2280-2290. https://doi.org/10.1016/j.biortech.2005.10. 042

Park SH, Lee JH, Ko SH et al (2000) Demulsification of oil-inwater emulsions by aerial spores of a Streptomyces sp. Biotechnol Lett 22:1389-1395. https://doi.org/10.1023/A: 1005660901558

Pavlaski P, Tarchi D, Sieber A (2001) On the monitoring of illicit vessel discharges: a reconnaissance study in the mediterranean sea. EC DG-Environ Dir Environ Qual Nat Resour Civ Prot Environ Accid Unit 56:700-718.

Peng H, Tremblay AY, Veinot DE (2005) The use of backflushed coalescing microfiltration as a pretreatment for the ultrafiltration of bilge water. Desalination 181:109-120. https://doi.org/10.1016/j.desal.2004.12.040

Raddadi N, Giacomucci L, Totaro G, Fava F (2017) Marinobacter sp. from marine sediments produce highly stable surface-active agents for combatting marine oil spills. Microb Cell Fact 16:1-13. https://doi.org/10.1186/ s12934-017-0797-3

Rincón GJ, La Motta EJ (2014) Simultaneous removal of oil and grease, and heavy metals from artificial bilge water using electro-coagulation/flotation. J Environ Manage 144:42-50. https://doi.org/10.1016/j.jenvman.2014.05.004

Rocha e Silva FCP, Roque BAC, Rocha e Silva NMPR et al (2017) Yeasts and bacterial biosurfactants as demulsifiers for petroleum derivative in seawater emulsions. AMB Express 7:202. https://doi.org/10.1186/s13568-017-0499-6

Rosario-Passapera R, Keddis R, Wong R et al (2012) Parvibaculum hydrocarboniclasticum sp. nov., a mesophilic, alkane-oxidizing alphaproteobacterium isolated from a deep-sea hydrothermal vent on the East Pacific Rise. Int J Syst Evol Microbiol 62:2921-2926

Sabati H, Motamedi H (2018) Investigation of the relationship between cell surface hydrophobicity and demulsifying capability of biodemulsifier producing bacteria. Front Biol 
(Beijing) 13:358-365. https://doi.org/10.1007/s11515018-1514-2

Salehizadeh H, Aida R, Kennedy K (2013) Demulsification capabilities of a Microbacterium species for breaking water-in-crude oil emulsions. African $\mathrm{J}$ Biotechnol 12:2019-2026. https://doi.org/10.5897/AJB11.3462

Santisi S, Gabriella G, Volta A, Bonsignore M, Mancini G, Quatrini P, Cappello S (2015) Isolation and characterization of oil- degrading bacteria from bilge water. Int $\mathbf{J}$ Microbiol Appl 2:45-49

Singleton DR, Sangaiah R, Gold A, et al (2006) Identification and quantification of uncultivated Proteobacteria associated with pyrene degradation in a bioreactor treating PAHcontaminated soil. Environ Microbiol 8(10):1736-1745

US EPA (2008) Cruise ship discharge assessment report (Assessment Report). (Report no. 842-R-07-005)

Wang Q, Garrity GM, Tiedje JM, Cole JR (2007) Naïve Bayesian classifier for rapid assignment of rRNA sequences into the new bacterial taxonomy. Appl Environ Microbiol 73:5261-5267. https://doi.org/10.1128/AEM.000625.2.1

Warr LN, Schlüter M, Schauer M, et al (2018) Nontronite-enhanced biodegradation of Deepwater Horizon crude oil by Alcanivorax borkumensis. Appl Clay Sci158:11-20

Wen Y, Cheng H, Lu LJ et al (2010) Analysis of biological demulsification process of water-in-oil emulsion by Alcaligenes sp. S-XJ-1. Bioresour Technol 101:8315-8322. https://doi.org/10.1016/j.biortech.2010. 05.088
Woytowich DL, Dalrymple CW, Gilmore FWBM (1993) Electrocoagulation (CURE) treatment of ship bilgewater for the United StatesCoast Guard in Alaska. Mar Technol Soc J 27:62-67

Wu J, Xu Y, Dabros T et al (2003) Effect of demulsifier properties on destabilization of water-in-oil emulsion. Energy Fuels 17:1554-1559. https://doi.org/10.1021/ef030113e

$\mathrm{Xu} \mathrm{Y,} \mathrm{Wu} \mathrm{J,} \mathrm{Dabros} \mathrm{T} \mathrm{et} \mathrm{al} \mathrm{(2005)} \mathrm{Optimizing} \mathrm{the} \mathrm{polyethylene}$ oxide and polypropylene oxide contents in diethylenetriamine-based surfactants for destabilization of a water-inoil emulsion. Energy Fuels 19:916-921. https://doi.org/10. 1021/ef0497661

Zenati B, Chebbi A, Badis A, et al (2018) A non-toxic microbial surfactant from Marinobacter hydrocarbonoclasticus SdK644 for crude oil solubilization enhancement. Ecotoxicol Environ Saf 154:100-107. https:// doi.org/10.1016/ j.ecoenv.2018.02.032

Zolfaghari R, Fakhru'l-Razi A, Abdullah LC, et al (2016) Demulsification techniques of water-in-oil and oil-in-water emulsions in petroleum industry. Sep Purif Technol 170:377-407. https://doi.org/10.1016/j.seppur.2016.06. 026

Publisher's Note Springer Nature remains neutral with regard to jurisdictional claims in published maps and institutional affiliations. 